\title{
Isoflurane inhibits endothelium-mediated nitric oxide relaxing pathways in the isolated perfused rabbit lung
}

Yoshiaki Oshima MD, Yuichi Ishibe MD, Naoto Okazaki PhD, Toru Sato MD

Purpose: The role of volatile anaesthetics on nitric oxide (NO)-dependent relaxation is unclear in the pulmonary circulation. We examined the effects of isoflurane on NO-dependent relaxation in isolated perfused rabbit lungs.

Methods: Eighteen rabbit lungs were perfused in a constant-flow recirculation manner. In study $\mid(n=12)$, acetylcholine (ACh, $4 \times 10^{-10}-10^{-8} \mathrm{M}$ ) or nitroglycerine (NTG, $6 \times 10^{-10}-10^{-8} \mathrm{M}$ ) was cumulatively injected into the pulmonary artery in the absence or presence of isoflurane (I, $2 \mathrm{MAC})$. In study $2(n=6)$. ACh was injected as in study I in the presence or absence of N $\omega$-nitro-L-arginine methyl ester (L-NAME, $100 \mu \mathrm{M}$ ), an NO synthesis blocker. In all expenments, indomethacin was administered to prevent formation of vasoactive prostanoid metabolites. and the pulmonary vessels were preconstricted with prostaglandin $F 2 \alpha(P G F 2 \alpha)$ infused before ACh or NTG injection. The ACh- or NTG-induced relaxation was expressed as \% decrease in PGF2 $\alpha$ preconstriction.

Results: Isoflurane at $2 \mathrm{MAC}$ attenuated the dose-dependent relaxation to $\mathrm{ACh}$ at doses of $4 \times 10^{-9} \mathrm{M}$ and $4 \times 10^{-8}$ $M$ from $27.8 \pm 4.3 \%$ and $38.8 \pm 5.3 \%$ to $17.0 \pm 3.5 \%$ and $25.5 \pm 4.9 \%$, respectively $(P<0.05)$. Isoflurane did not change the dose-dependent relaxation to NTG and L-NAME abolished the ACh-induced relaxation.

Conclusion: Isoflurane inhibited NO-dependent relaxation in the pulmonary circulation at a site distal to the endothelial cell receptor-mediated responses but proximal to guanylate cyclase activation of vascular smooth muscle. Acetylcholine-induced relaxation in isolated perfused rabbit lungs was regulated primarily by NO.

Objectif : Nous connaissons mal l'influence des anesthésiques volatils sur la relaxation de la circulation pulmonaire dépendante du monoxyde d'azote $(\mathrm{NO})$. Cette étude analyse les effets de l'isoflurane sur la relaxation NO-dépendante de poumons perfusés de lapins.

Méthodes : Dix-huit poumons de lapins ont été perfusés par recirculation à débit constant. Dans l'étude 1 $(n=12)$, on a injecté de l'acétylcholine (ACh, $\left.4 \times 10^{-1}-10^{-8} \mathrm{M}\right)$ ou de la nitroglycérine (NTG, $\left.6 \times 10^{-10}-10^{-8} \mathrm{M}\right)$ avec ou sans isoflurane $(1,2 \mathrm{MAC})$. Dans l'étude $2,(n=6)$, l'ACh a été injectée seule comme dans l'étude I ou

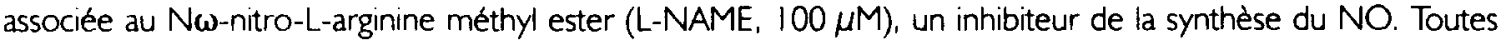
les expériences ont comporté l'administration d'indométhacine pour prévenir la formation de métabolites protanoïdes vasoactifs ainsi que la constriction préalable avec de la prostaglandine $F 2 \alpha$ (PGF2 $\alpha$ ) administrée en perfusion avant l'injection de l'ACh et de la NTG. La relaxation induite par ACh ou NTG était exprimée en fonction de la diminution du pourcentage de constriction provoquée par la PGF2 $\alpha$.

Résultats : Lisoflurane à 2 MAC atténuait la relaxation à l'ACh proportionnellement aux doses de $4 \times 10^{-9}$ et $4 \times 10^{-8} \mathrm{M}$ respectivement de $27,8 \pm 4,3 \%$ et $38,8 \pm 5,3 \%$ à $17,0 \pm 3,5 \%$ et $25,5 \pm 4,9 \%(P<0,05)$. Lisoflurane ne modifiait la relaxation de la circulation pulmonaire NO-dépendante à la NTG; le L-Name abolissait la relaxation induite par l'ACH.

Conclusion : L'isoflurane inhibe la relaxation NO-dépendante dans la circulation pulmonaire à un site distal à celui des réponses transmises par médiation du récepteur endothélial cellulaire mais proximal à l'activation par le guanylate cyclase du muscle vasculaire lisse. Le NO est le régulateur primaire de la relaxation induite par l'ACh dans le poumon de lapin perfusé.

From the Department of Anesthesiology, Faculty of Medicine, Tottori University, 36-1 Nishi-machi, Yonago 683, Japan.

Address correspondence to: Dr. Yoshiaki Oshima, Phone: 81-859-34-8129; Fax: 81-859-34-8088; E-mail: yoshimat@grape.med tottori-u.ac.jp Accepted for publication May 14, 1997. 


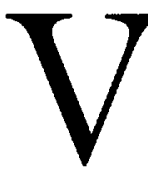

ASCULAR endothelium appears to play an important role in the regulation of vascular smooth muscle tone by releasing vasoactive substances such as nitric oxide (NO) in response to various stimuli. ${ }^{1}$ Acetylcholine (ACh) activates NO synthesis, releases $\mathrm{NO}$ and then increases the cGMP concentration in vascular smooth muscles to cause vasodilatation. ${ }^{1}$ Volatile anaesthetics have marked effects on vascular control and haemodynamics. Volatile anaesthetics inhibit endothelium-dependent relaxation induced by $\mathrm{ACh}$ in systemic vessel rings such as the aorta, femoral artery, carotid artery and mesenteric artery. ${ }^{2-9}$ This inhibition may seem somewhat counterintuitive to anaesthetists who have thought of volatile anaesthetics as pure vasodilators. In the pulmonary circulation, however, the role of volatile anaesthetics on endothelium-dependent relaxation is less clear. The systemic circulation is a high pressure, high resistance system. On the contrary, the pulmonary circulation is characterized by a low pressure system and an ability to constrict in response to hypoxia. This response to hypoxia, hypoxic pulmonary vasoconstriction (HPV), is the opposite of the effects observed in the systemic circulation, where hypoxia produces dilatation rather than constriction. Volatile anaesthetics are often considered to be pulmonary vasodilators because they have generally been shown to inhibit the magnitude of HPV. ${ }^{10,11}$

Furthermore, $\mathrm{ACh}$-induced relaxation that is resistant to NO synthase inhibitors has recently been reported, and such relaxation may be mediated by an endothelium-derived hyperpolarizing factor (EDHF) that is distinct from NO. ${ }^{12}$ The relative importance of NO and EDHF in the endothelium-dependent relaxation in various types of vessels has been actively investigated. Nitric oxide primarily exerts its action on ACh-induced relaxation in the large, conduit arteries, ${ }^{12,13}$ while EDHF acts predominantly in small arterial beds such as the mesenteric artery. ${ }^{13,14}$

In the present study, using isolated perfused rabbit lungs, we examined whether isoflurane affected $\mathrm{ACh}$ induced endothelium-dependent relaxation in the pulmonary circulation. Second, we examined which factor, NO or EDHF, was the primary determinant of vascular calibre under $\mathrm{ACh}$-induced relaxation in the pulmonary circulation. These findings are relevant because of the extensive clinical and investigational use of isoflurane anaesthesia.

\section{Methods}

This study conformed to Guidelines for Animal Experimentation in Faculty of Medicine, Tottori University. A standard in vitro perfused rabbit lung preparation ${ }^{15,16}$ was modified as described in the following.

\section{Preparation of isolated rabbit lungs}

Adult female Japanese white rabbits weighing $2.3 \pm 0.1 \mathrm{~kg}$ (mean \pm SEM) were anaesthetized with 20 $\mathrm{mg} \cdot \mathrm{kg}^{-1}$ pentobarbital $i v$ and $35 \mathrm{mg} \cdot \mathrm{kg}^{-1}$ ketamine im, and anticoagulated with $500 \mathrm{IU} \cdot \mathrm{kg}^{-1}$ heparin iv. To prevent formation of vasoactive prostanoid metabolites, 10 $\mathrm{mg} \cdot \mathrm{kg}^{-1}$ indomethacin $i v$ was administered. The neck and sternal regions were infiltrated with xylocaine $1 \%$. A tracheostomy was performed and the lungs were mechanically ventilated with a Harvard ventilator (model 681, Harvard Apparatus, South Natrick, MA) at a rate of 40 breaths $\cdot \mathrm{min}^{-1}$ and a tidal volume of $10 \mathrm{ml} \cdot \mathrm{kg}^{-1}$ with a gas mixture consisting of $\mathrm{O}_{2} 21 \%, \mathrm{CO}_{2} 5 \%$ and balance nitrogen. Positive end-expiratory pressure of $2 \mathrm{~cm} \mathrm{H}_{2} \mathrm{O}$ was applied. A sternotomy was performed, and the ribs were retracted exposing the heart and lungs. An incision was made into the right ventricle, and then the rabbits were killed by rapid withdrawal of blood. A cannula was inserted into the main pulmonary artery via the incision in the right ventricle and secured with an umbilical tape. The ligature around the pulmonary artery cannula also included the aorta, preventing loss of perfusate into the systemic circulation and effectively isolating the pulmonary circulation. An incision was made in the apex of the left ventricle and a cannula was inserted into the left atrium and secured by a ligature around the apex of the heart. The pulmonary circulation was first perfused in a nonrecirculating manner with bovine serum albumin 3\% dissolved in physiological salt solution (PSS) until the effluent was clear. Then, autologous blood was added to the PSS, and the lungs were perfused in a recirculating manner with a peristaltic pump (model 1215, Harvard Apparatus) at a flow rate of $30 \mathrm{ml} \cdot \mathrm{kg}^{-1}$ body weight $\mathrm{min}^{-1}$ monitored with an electromagnetic blood flowmeter (MF-1200, Nihon Kohden, Tokyo, Japan). The PSS contained $119 \mathrm{mM} \mathrm{NaCl}, 4.7 \mathrm{mM} \mathrm{KCl}, 1.17$ $\mathrm{mM} \mathrm{MgSO}_{4}, 22.61 \mathrm{mM} \mathrm{NaHCO}{ }_{3}, 1.18 \mathrm{mM} \mathrm{KH}_{2} \mathrm{PO}_{4}$ and $3.2 \mathrm{mM} \mathrm{CaCl}$, and to each $100 \mathrm{ml}$ of this stock solution were added $100 \mathrm{mg}$ dextrose $20 \mathrm{mU}$ insulin, 1 $\mathrm{ml} \mathrm{NaHCO}, 8 \%$ and $3 \mathrm{~g}$ bovine serum albumin. The final perfusate contained $50 \mathrm{ml}$ PSS and $20 \mathrm{ml}$ autologous blood, with a haematocrit of about $8 \%$. The perfusate reservoir temperature was kept at $38^{\circ} \mathrm{C}$ with a heated water bath. The pulmonary artery pressure (PAP), left atrial pressure and airway pressure were measured continuously via side holes in the cannula with pressure transducers (P23 ID, Gould, Oxnard, CA) and recorded on a polygraph (type 361, NEC San-ei, Tokyo, Japan). All pressures referred to the level of the left atrium. The level of the drainage tube from the left atrium was adjusted to maintain the left atrial pressure at 0 $\mathrm{mmHg}$. The isolated lung preparation remained in the thoracic cavity, which was covered with transparent vinyl 
wrapping material to maintain the humidity surrounding the lungs, and an infrared light was applied to maintain the chest cavity temperature at approximately $38^{\circ} \mathrm{C}$. After institution of the perfusion circuit, additional indomethacin producing the final circulating concentration of $20 \mu \mathrm{M}$ was added to the reservoir, and the animals were allowed to stabilize for $30 \mathrm{~min}$ before proceeding to the experimental protocol. In studies $\mathrm{I}$ and 2, perfusate haematocrit, $\mathrm{pH}, \mathrm{PCO}_{2}$ and $\mathrm{PO}_{2}$ were measured at the beginning and during experiments, from reservoir samples, with a blood gas analyser (JBA-7, Jookoo, Tokyo, Japan). Perfusate $\mathrm{pH}$ was maintained between 7.30 and 7.50 by adding small volumes of $\mathrm{NaHCO}_{3}$.

\section{Study 1: effects of isoflurane on vasoreactivity}

Twelve perfused lungs were divided into two groups treated with $\mathrm{ACh}$ and isoflurane (ACh-ISO group, $\mathbf{n}=6$ ) or NTG and isoflurane (NTG-ISO group, $n=$ $6)$. The ACh- or NTG-induced relaxation was examined during ventilation with randomized concentrations of isoflurane $(0,1$ and $2 \mathrm{MAC})$. Prostaglandin F2 $\alpha$ (PGF2 $\alpha$ ) was continuously infused at a rate of $5.0-40 \mathrm{nmol} \cdot \mathrm{min}^{-1}$ into the circuit proximal to the pulmonary artery until the PAP was increased to 30 $\mathrm{mmHg}$. After a stable increase in the PAP was achieved, the drug vehicle $(0.5 \mathrm{ml}$ saline $)$ and $A C h$ or NTG dissolved in $0.5 \mathrm{ml}$ saline were injected into the circuit proximal to the pulmonary artery in a cumulative fashion in three doses, which produced final circulating concentrations of $4 \times 10^{-10} \mathrm{M}, 4 \times 10^{-9} \mathrm{M}$ and $4 \times 10^{-8} \mathrm{M}$ for ACh or $6 \times 10^{-10} \mathrm{M}, 6 \times 10^{-9} \mathrm{M}$ and $6 \times 10^{-8} \mathrm{M}$ for NTG, respectively. Each dose was injected after the maximal effect of the previous dose was achieved. PGF2 $\alpha$ was discontinued after the maximal effect of ACh or NTG was achieved by the dose of $4 \times 10^{-8} \mathrm{M}$ or $6 \times 10^{-8} \mathrm{M}$, respectively. After the baseline pressure had returned to the control level by discontinuation of PGF2 $\alpha, 15$ min were allowed for equilibration at every new inspiratory concentration of isoflurane. The minimum alveolar concentration (MAC) for rabbits was assumed to be $2.05 \%$ for isoflurane, ${ }^{17}$ and a vaporizer (type I MK III, Acoma, Tokyo, Japan) was used to deliver isoflurane vapour. The endtidal concentration of isoflurane was measured continuously with an anaesthetic gas monitor (type 1304, Brüel \& Kjær, Naerum, Denmark). The anaesthetic concentration in the perfusate was equilibrated with that in the lungs within $10 \mathrm{~min}$ after changing the concentration. ${ }^{10}$ At the end of the study and immediately after completion of perfusion, the lungs were removed. After weighing the wet weight, the whole lungs were dried for $72 \mathrm{hr}$ and reweighed. The simple, blood-inclusive, wet-to-dry lung weight ratio was then calculated by (wet lung weight - dry lung weight $) /$ dry lung weight $\left(\mathrm{ml} \cdot \mathrm{g}^{-1}\right)$.

\section{Study 2: effects of No-nitro-L-arginine methyl ester (L-NAME) on vasoreactivity}

Six perfused lungs were studied. As in study 1 , the pulmonary vasculature was preconstricted with PGF2 $\alpha$, and then drug vehicle and ACh $\left(4 \times 10^{-10} \mathrm{M}, 4 \times 10^{-9}\right.$ $\mathrm{M}$ and $4 \times 10^{-8} \mathrm{M}$ ) were injected cumulatively into the pulmonary artery after the maximal effect of the previous dose had been achieved. PGF2 $\alpha$ was discontinued after the maximal effect of ACh at the dose of $4 \times 10^{-8}$ $M$ was achieved. After the baseline pressure had returned to the control level by discontinuation of PGF $2 \alpha$, L-NAME producing a final circulating concentration of $100 \mu \mathrm{M}$ was added to the reservoir. After 30min equilibration, the above protocol of $\mathrm{ACh}$ injections was repeated.

\section{Statistics}

The data are shown as mean \pm SEM. The values within a group were compared with one-way analysis of variance and, if a statistical difference was observed, a multiple-comparison test was performed by Scheffe's F-test. The values between groups were compared by unpaired $t$ test. Differences were considered significant at $P<0.05$.

\section{Results}

The general conditions did not differ among the three groups throughout experiments. Average data were as follows: $\mathrm{pH} 7.361 \pm 0.008, \mathrm{PaCO}_{2} 35.3 \pm 0.6 \mathrm{mmHg}$, $\mathrm{PaO}_{2} 146.5 \pm 2.8 \mathrm{mmHg}$, base excess $-2.9 \pm 0.5$ and perfusate haematocrit $7.9 \pm 0.2 \%$. Peak airway pressures (data not shown) were not altered by the protocol and administration of isoflurane or L-NAME. The relaxant response to ACh or NTG was expressed as \% decrease in PGF2 $\alpha$ preconstriction, which was calculated with the following formula:

$\left(\mathrm{PAP}_{\mathrm{PGF} 2 \alpha}-\mathrm{PAP}_{\mathrm{ACh} \text { or NTG }}\right) /\left(\mathrm{PAP}_{\mathrm{PGF} 2 \alpha}-\right.$ baseline $\left.\mathrm{PAP}\right) \times 100 \%$.

\section{Study 1}

When isoflurane was at 0,1 and $2 \mathrm{MAC}$, the baseline PAP before infusing PGF $2 \alpha$ was $11.3 \pm 1.0 \mathrm{mmHg}, 11.6 \pm$ $1.4 \mathrm{mmHg}$ and $11.4 \pm 1.6 \mathrm{mmHg}$ in the ACh-ISO group; and $12.3 \pm 1.6 \mathrm{mmHg}, 11.7 \pm 1.1 \mathrm{mmHg}$ and $12.2 \pm 2.3 \mathrm{mmHg}$ in the NTG-ISO group, respectively. There were no differences in baseline PAP between groups with and without administration of isoflurane. The wet-to-dry lung weight ratio $\left(\mathrm{ml} \cdot \mathrm{g}^{-1}\right)$ was $5.27 \pm$ 0.23 in the ACh-ISO group, and $5.06 \pm 0.30$ in the NTG-ISO group; there was no difference between the two groups. 
After administration of $0 \mathrm{MAC}$ isoflurane, dosedependent relaxation to $\mathrm{ACh}$ at doses of $4 \times 10^{-10} \mathrm{M}$, $4 \times 10^{-9} \mathrm{M}$ and $4 \times 10^{-8} \mathrm{M}$ was $13.3 \pm 2.4 \%, 27.8 \pm$ $4.3 \%$ and $38.8 \pm 5.3 \%$, respectively: when isoflurane was at $2 \mathrm{MAC}$, the dose-dependent relaxation to ACh at doses of $4 \times 10^{-10} \mathrm{M}, 4 \times 10^{-9} \mathrm{M}$ and $4 \times 10^{-8}$ $M$ was $8.2 \pm 2.0 \%, 17.0 \pm 3.5 \%$ and $25.5 \pm 4.9 \%$, respectively. These showed that $2 \mathrm{MAC}$ isoflurane $(P<0.05)$ decreased the dose-dependent relaxation to $\mathrm{ACh}$ at doses of $4 \times 10^{-9} \mathrm{M}$ and $4 \times 10^{-8} \mathrm{M}$ (Figures 1B, 2A). Dose-dependent relaxation to

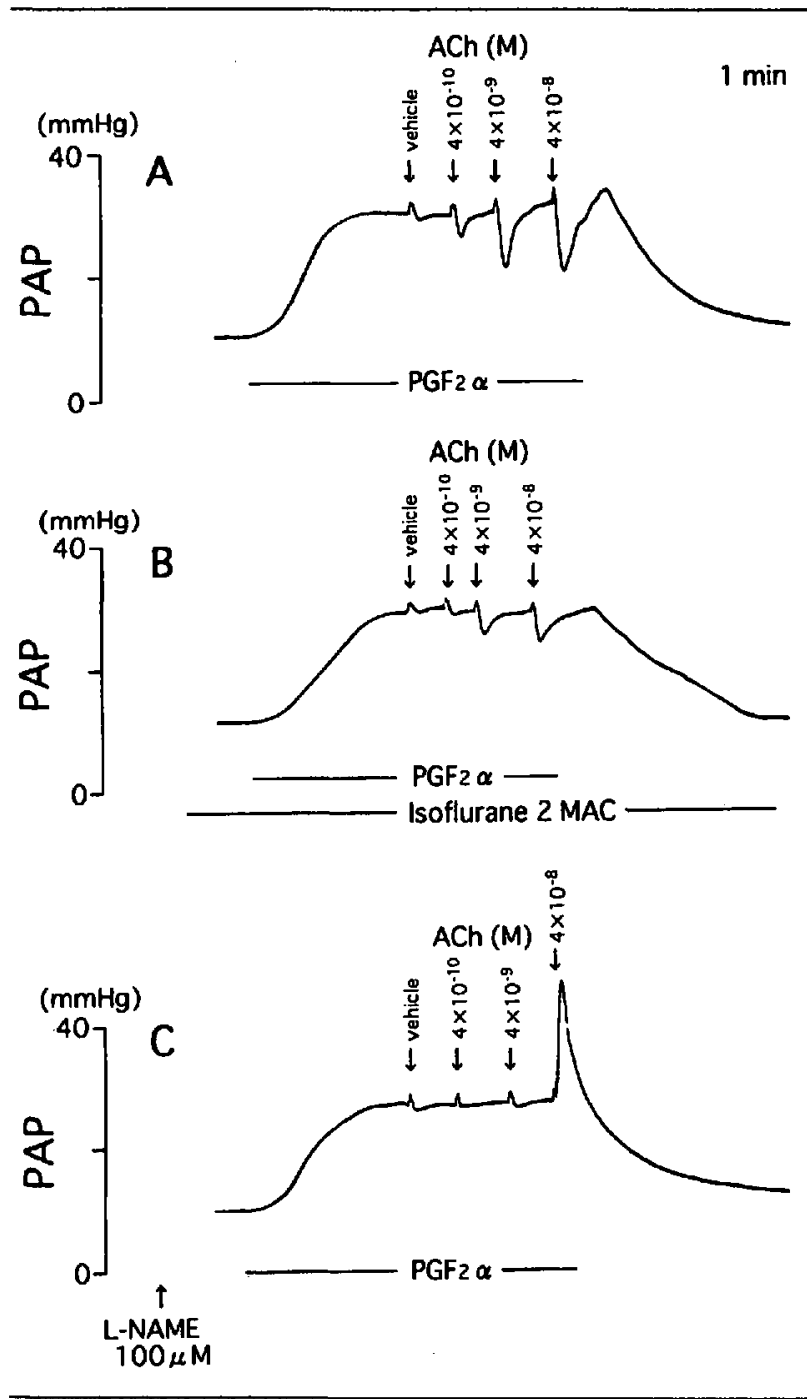

FIGURE 1 Representative tracings of responses to acetylcholine (ACh) at doses from $4 \times 10^{-10}$ to $10^{-8} \mathrm{M}$ in perfused lungs. $A$ : Responses to $\mathrm{ACh}$ without isoflurane: volume loading with drug vehicle $(0.5 \mathrm{ml}$ saline) increases pulmonary arterial pressure (PAP) transiently, and ACh decreases the PAP in a dose-dependent manner. B: Responses to $\mathrm{ACh}$ with isoflurane at $2 \mathrm{MAC}$ : dosedependent relaxation to $\mathrm{ACh}$ is attenuated. $\mathrm{C}$ : Responses to $\mathrm{ACh}$ with $100 \mu \mathrm{M}$ L-NAME: the dose-dependent relaxations to $\mathrm{ACh}$ are abolished, and $\mathrm{ACh}$ at the dose of $4 \times 10^{-8} \mathrm{M}$ is turned to constrict pulmonary arteries.
NTG $\left(6 \times 10^{-10}-10^{-8} \mathrm{M}\right)$ was not changed by the presence of isoflurane (Figure $2 \mathrm{~B}$ ).

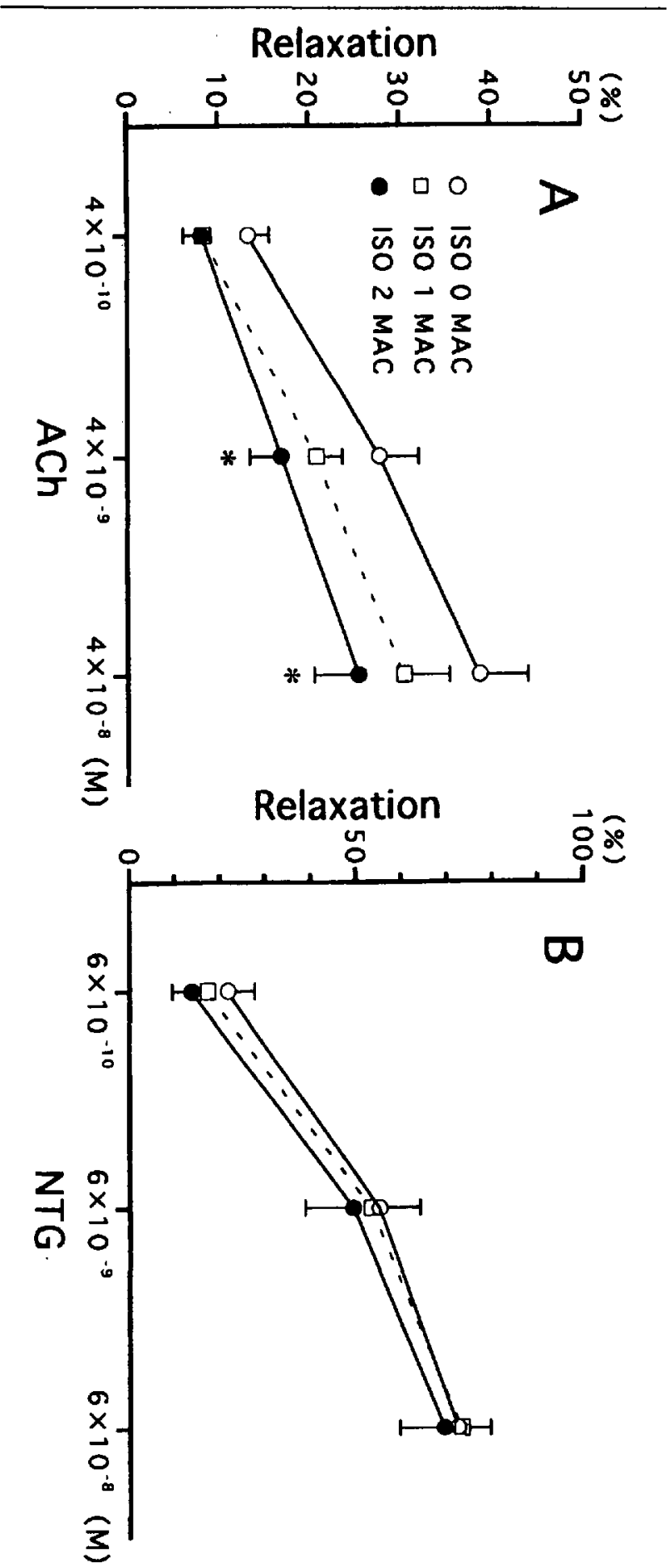

FIGURE 2 Dose-response curves to acetylcholine (ACh) (A) or nitroglycerine (NTG) (B) treated with isoflurane (ISO) at 0 to 2 MAC. The relaxant response to ACh or NTG is expressed as percentage of contractions induced by prostaglandin F2 $\alpha(P G F 2 \alpha)$. ${ }^{*} P<0.05$ compared with 0 MAC. $\mathrm{n}=6$. 
Study 2

The baseline PAP betore intusing PGF2 was $\mathrm{I} 3.4 \pm$ $0.6 \mathrm{mmHg}$ and $13.3 \pm 0.7 \mathrm{mmHg}$ without and with administration of L-NAME, respectively; there was no statically significant difference.

After administration of L-NAME, ACh-induced relaxation was abolished and an ACh dose of $4 \times 10^{-8}$ $M$ increased the PAP (Figures 1C, 3).

\section{Discussion}

There were two major findings in the present experiments with isolated perfused rabbit lungs. First, isoflurane at $2 \mathrm{MAC}$ inhibited $\mathrm{ACh}$-induced relaxation in the pulmonary circulation, but not NTG-induced relaxation. Second, by the administration of the NO synthesis blocker L-NAME, ACh-induced vascular relaxation was abolished and high-dose $\mathrm{ACh}$ caused constriction of the pulmonary arteries.

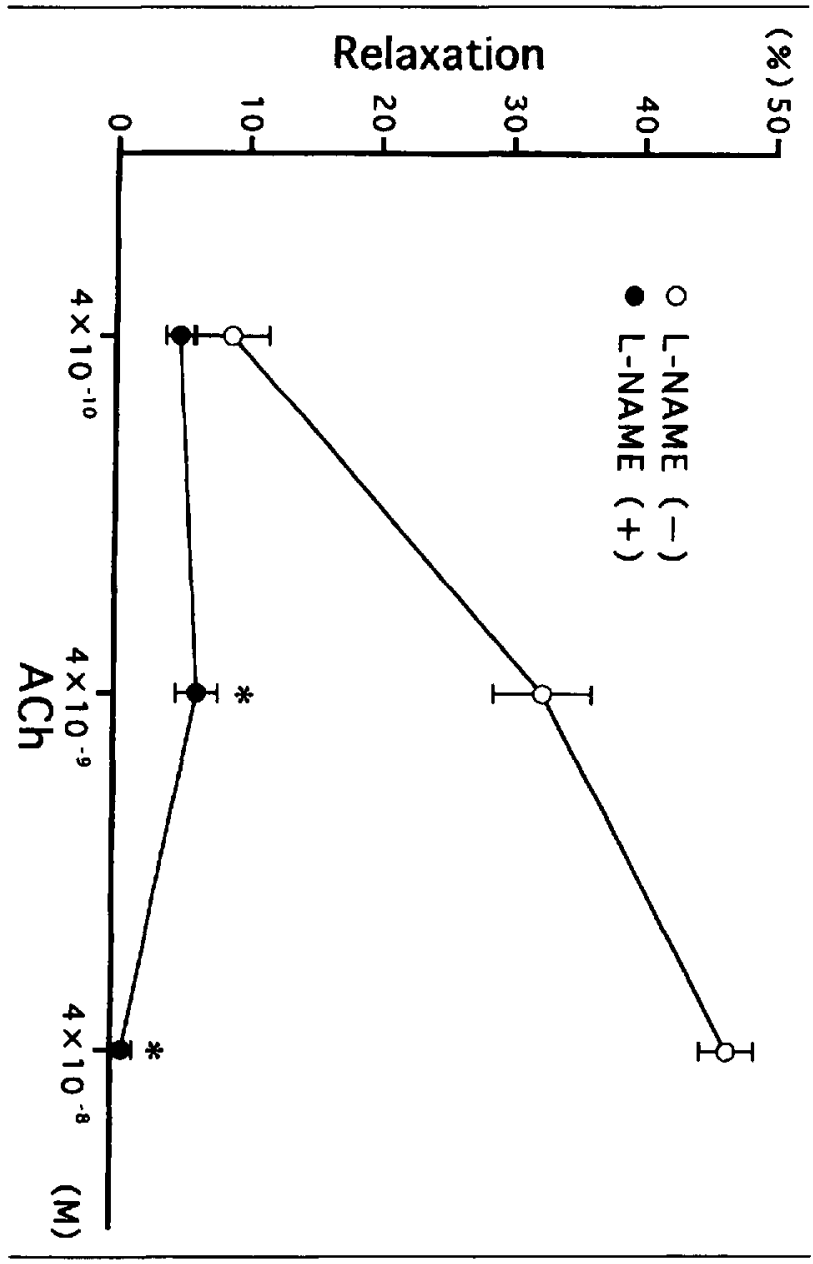

FIGURE 3 Dose-response curves to acetylcholine (ACh) with and without $N \omega$-nitro-L-arginine methyl ester (L-NAME). The relaxant response to $\mathrm{ACh}$ is expressed as percentage of contractions induced by prostaglandin F2 $\alpha$ (PGF2 $\alpha$ ).

${ }^{\star} P<0.01$ compared with L-NAME (-). $n=6$.
In larger vessels such as the aorta, NO plays the dominant role in $\mathrm{ACh}$-induced endothelial relaxation. ${ }^{12,13}$ From previous studies on vascular rings of conduit arteries, volatile anaesthetics exerting endothelium-dependent relaxation have different inhibitory mechanisms: isoflurane inhibits NO synthesis mainly in the endothelium; halothane inhibits NO action in vascular smooth muscles; and sevoflurane produces oxygen-free radicals that deactivate NO action., ${ }^{4,7}$ Nitric oxide is formed from the amino acid L-arginine by NO synthase and activation is calcium-dependent. ${ }^{1}$ When administered with the fluorescent $\mathrm{Ca}^{2+}$ indicator fura-2, halothane and isoflurane decrease intracellular calcium in bovine aortic endothelial cells stimulated by bradykinin. ${ }^{18}$ The resultant decrease in $\mathrm{Ca}^{2+}$ availability is likely to interfere with NO production by modulating NO synthase activity.

In the mesenteric resistance arteries, EDHF acts preferably on $\mathrm{ACh}$-induced relaxation than does NO. ${ }^{13,14}$ Volatile anaesthetics inhibit the vasodilating actions not only of NO but also of EDHF., ${ }^{9,19}$ However, when NO is not deactivated, the inhibitory action of volatile anaesthetics on $\mathrm{ACh}$-induced relaxation is weak in the mesenteric resistance arteries. ${ }^{20-22}$

In the pulmonary circulation, volatile anaesthetics may attenuate endothelium-dependent relaxation, although the results are conflicting. When pulmonary vascular pressure-flow plots are generated in chronically instrumented dogs, halothane anaesthesia $(1.2 \%$ endtidal concentration) abolished the pulmonary vasodilating actions of bradykinin, an endothelium-dependent vasodilator, and of nitroprusside, an endothelium-independent vasodilator. ${ }^{23}$ In the case of isoflurane anaesthesia, an end-tidal concentration of $1.9 \%$ attenuated the pulmonary vasodilator response of bradykinin, but enhanced the pulmonary vasodilator response of SIN-I, an endothelium-independent vasodilator. ${ }^{24}$ On the other hand, in vascular rings of the rat main pulmonary artery, halothane at $2 \mathrm{MAC}$ did not inhibit exogenous NO-induced relaxation ${ }^{25}$ In the present study with isolated perfused rabbit lungs, $2 \mathrm{MAC}$ isoflurane inhibited ACh-induced relaxation in the pulmonary circulation, but did not change NTG-induced relaxation. Acetylcholine activates NO synthesis, releases $\mathrm{NO}$ and then activates guanylate cyclase, while NTG, an endothelium-independent vasodilator, directly activates guanylate cyclase. Both agents increase the cGMP concentration in vascular smooth muscles to cause vasodilation. ${ }^{1}$ We speculate that 2 MAC isoflurane blocks endothelium-dependent relaxation in the pulmonary circulation as well as in the conduit arteries such as the aorta, through inhibiting NO synthesis mainly in the endothelium of pulmonary vessels. When examined under the bioassay system using bovine aorta, both halothane and isoflurane interfere with the stability of 
NO rather than with its secretion, release or action. ${ }^{26,27}$ Direct measurement of NO would resolve the speculation that isoflurane decreases NO synthesis in the endothelium of pulmonary vessels.

Endothelium-derived hyperpolarizing factor is believed to cause hyperpolarization and results in relaxation by opening $\mathrm{K}^{+}$channels. ${ }^{14}$ According to experimental studies on vascular rings of pulmonary vessels, $\mathrm{ACh}$-induced relaxation of the main pulmonary artery is reduced to $20-25 \%$ in the presence of haemoglobin and methylene blue, which are blockers of $\mathrm{NO}$ action. ${ }^{12}$ Furthermore, the $\mathrm{ACh}$-induced relaxation disappears in the presence of another blocker, L-NAME. ${ }^{13}$ It seems logical to assume that endothelium-dependent relaxation which is resistant to inhibitors of the L-arginineNO pathway is mediated by EDHF. This interpretation is supported by the observation that L-NAME-resistant relaxation was not observed in high- $\mathrm{K}^{+}$solutions, where endothelium-dependent hyperpolarization is absent. ${ }^{28}$ In vascular smooth muscle cells of the rat, the $\mathrm{ACh}$ induced hyperpolarizing response is 100 -fold weaker in the main pulmonary artery than in the aorta, and negligibly small in the intralobular small pulmonary artery. ${ }^{28}$ In the present experiments, the administration of NO synthesis blocker L-NAME abolished the ACh-induced vascular relaxation, and the action of high-dose $\mathrm{ACh}$ was converted from dilator to constrictor. These results suggest that $\mathrm{ACh}$-induced vascular relaxation is regulated primarily by $\mathrm{NO}$ in isolated perfused rabbit lungs, although the membrane potential of the smooth muscle cell was not directly measured.

Models in vipo include a number of factors that can modify pulmonary vascular tone indirectly, and these preparations are useful in evaluating the net effects of the drugs on both pulmonary and systemic haemodynamics. We selected the constant-flow in vitro model in the present study. An in vitro constant-flow perfused lung preparation is suitable for examining the direct effect of anaesthetics on pulmonary vascular tone because a high concentration of anaesthetic may be administered without the confounding effects of circulatory depression. Because of the constant perfusion and constant left atrial pressure $(0 \mathrm{mmHg})$, pulmonary vascular resistance was directly proportioned to and increased together with the PAP. Each experiment lasted for up to $2.5 \mathrm{hr}$, but no oedema was observed (dry/wet lung weight determinations). High-dose ACh causes a rapid increase in PAP in rabbit pulmonary circulation and induces pulmonary oedema. This process is prevented by indomethacin, ${ }^{16}$ because $\mathrm{ACh}$ stimulates the release of thromboxane $\mathrm{A} 2$ from the vascular endothelium, which causes constriction of the intrapulmonary resistance arteries. ${ }^{29}$ The endothelial cells can release several vasodilators such as prostacyclin, $\mathrm{NO}$ and
EDHF. Halothane increases prostacyclin release in bovine pulmonary artery endothelial cells, ${ }^{30}$ while inhibits bradykinin-stimulated prostacyclin production in bovine aortic endothelial cells. ${ }^{31}$ Our experimental setup involves the testing $\mathrm{NO}$ and $\mathrm{EDHF}$, because prostaglandin synthesis is inhibited by indomethacin. In addition, in experiments of pulmonary vascular rings, the action of isoflurane in blocking bradykinin-induced vasorelaxation is abolished without indomethacin treatment. $^{32}$

In conclusion, $2 \mathrm{MAC}$ isoflurane inhibited NOdependent relaxation in the pulmonary circulation at a site distal to the endothelial cell receptor-mediated responses but proximal to guanylate cyclase activation of vascular smooth muscle. Endothelium-dependent relaxation induced by $\mathrm{ACh}$ was regulated primarily by NO in the isolated perfused rabbit lungs. The observed effects have important clinical implications in regulating pulmonary vascular tone during surgery and anaesthesia.

\section{Acknowledgments}

The authors thank Drs M. Masutani, Y. Matsubara, K. Tsuda, S. Hori, J. Hirosawa and K. Kawamura, Department of Anesthesiology, Faculty of Medicine, Tottori University for their encouraging us to carry out this study.

\section{References}

1 Moncada S, Palmer RMJ, Higgs EA. Nitric oxide: physiology, pathophysiology and pharmacology. Pharmacol Rev 1991; 43: 109-42.

2 Muldoon SM, Hart $\Pi_{3}$, Bowen KA, Freas W. Attenuation of endothelium-mediated vasodilation by halothane. Anesthesiology 1988; 68: 31-7.

3 Su $\Gamma$, Zhang CC. Intracellular mechanisms of halothane's effect on isolated aortic strips of the rabbit. Anesthesiology 1989; 71: 409-17

4 Toshida K, Okabe E. Selective impairment of endothelium-dependent relaxation by sevoflurane: oxygen free radicals participation. Anesthesiology 1992; 76: 440-7.

5 Uggeri MJ, Proctor GJ, Johns RA. Halothane, enflurane, and isoflurane attenuate both receptor and non-receptor mediated EDRF production in rat thoracic aorta. Anesthesiology 1992; 76: 1012-7.

6 Toda $H$, Nakamura $K$, Hatano $Y$, Nishiwada $M$, Kakuyama $M$, Mori $K$. Halothane and isoflurane inhibit endothelium-dependent relaxation elicited by acetylcholine. Anesth Analg 1992; 75: 198-203.

7 Hart $L$, Jing $M$, Bina S, Freas W, Van Dyke RA, Muldoon $S M$. Effects of halothane on EDRF/cGMP-mediated vascular smooth muscle relaxations. Anesthesiology 1993; 79: 323-31.

8 Nakamura $K$, Terasako $K$, Toda $H$, et al. Mechanisms of inhibition of endothelium-dependent relaxation by 
halothane, isoflurane, and sevoflurane. Can J Anaesth 1994; 41: 340-6.

9 Akata $T$, Nakashima M, Kodama K, Boyle WA III, Takabashi $S$. Effects of volatile anesthetics on acethylcholine-induced relaxation in the rabbit mesenteric resistance artery. Anesthesiology 1995; 82: 188-204.

10 Marshall C, Lindgren L, Marshall BE. Effects of halothane, enflurane, and isoflurane on hypoxic pulmonary vasoconstriction in rat lungs in vitro. Anesthesiology 1984; 60: 304-8.

11 Isbibe $\Upsilon$, Gui $X$, Uno $H$, Shiokawa $\Upsilon$, Umeda $T$, Suekane $K$. Effect of sevoflurane on hypoxic pulmonary vasoconstriction in the perfused rabbit lung. Anesthesiology 1993; 79: 1348-53.

12 Chen G, Suzuki $H$, Weston AH. Acetylcholine releases endothelium-derived hyperpolarizing factor and EDRF from the rat blood vessels. Br J Pharmacol 1988; 95: 1165-74.

13 Nagao T, Illiano S, Vanboutte PM. Heterogeneous distribution of endothelium-dependent relaxations resistant to $\mathrm{N}^{\mathrm{G}}$-nitro-L-arginine in rats. Am J Physiol 1992; 263: $\mathrm{Hl} 090-4$

14 Adeagbo ASO, Triggle CR. Varying extracellular $\left[\mathrm{K}^{+}\right]$: a functional approach to separating EDHF- and EDNOrelated mechanisms in perfused rat mesenteric arterial bed. J Cardiovasc Pharmacol 1993; 21 : 423-9.

15 Marshall C, Ishibe $\Upsilon$, Marshall BE. A combined in vivo/in pitro small animal model for studying pulmonary responses. Methods Find Exp Clin Pharmacol 1988; 10: 5-11.

16 Catravas JD, Buccafusco J, Kashef HE. Effects of acetylcholine in the pulmonary circulation of rabbits. J Pharmacol Exp Ther 1984; 231: 236-41.

17 Drummond JC. MAC for halothane, enflurane, and isoflurane in the New Zealand white rabbit: and a test for the validity of MAC determinations. Anesthesiology $1985 ; 62: 336-8$.

18 Simoneau $C$, Thuringer $D$, Cai S, Gameau $L$, Blaise $G$, Sauvé $R$. Effects of halothane and isoflurane on bradykinin-evoked $\mathrm{Ca}^{2+}$ influx in bovine aortic endothelial cells. Anesthesiology 1996; 85: 366-79.

19 Lischke $V$, Busse $R$, Hecker $M$. Inhalation anesthetics inhibit the release of endothelium-derived hyperpolarizing factor in the rabbit carotid artery. Anesthesiology $1995 ; 83: 574-82$.

20 Tsukiyama $\Upsilon$, Iranami $H$, Tamamoto $M$, Nisbiura $N$, Hatano $\Upsilon$. Halothane and isoflurane do not inhibit the relaxant response response elicited by acetylcholine in perfused rat mesenteric arterial beds. Anesthesiology 1993; 79: A660.

21 Iranami $H$, Tsukiyama $Y$, Tamamoto $M$, Tsuchiyama $Y$ Hatano $\Upsilon$. Differences in the inhibition by halothane of acetylcholine-induced relaxation in rat aorta and mesenteric artery. Anesthesiology 1993; 79: A661.

22 Tsukiyama $\Upsilon$, Iranami $H$, Tsucbiyama $\Upsilon$, Nishiura $N$, Hatano $\Upsilon$. The endothelium derived hyperpolarization factor-mediated vasodilation is inhibited by halothane in rat mesenteric arterial beds. Anesthesiology 1994; 81: A678.

23 Murray PA, Febr DM, Chen BB, et al. Differential effects of general anesthesia on CGMP-mediated pulmonary vasodilation. J Appl Physiol 1992; 73: 721-7.

24 Gambone LM, Fuziwara $\Upsilon$, Murray PA. Endotheliumdependent CGMP-mediated pulmonary vasodilation is selectively attenuated during isoflurane anesthesia compared to the conscious state. Anesthesiology 1993; 79: A681.

25 Sugimori $K$, Comporesi EM, Hakim TS. The effect of halothane on nitric oxide-induced relaxation in rat pulmonary artery and aorta. Anesthesiology 1995; 83: Al195.

26 Blaise $G, T o Q$ Parent $M$, Lagarde B, Asenjo R, Saupé $R$. Does halothane interfere with the release, action, or stability of endothelium-derived relaxing factor/nitric oxide. Anesthesiology 1994; 80: 417-26.

27 Blaise $G, T o Q$ Isoflurane decreases EDRF/NO action but not its production. Anesthesiology 1993; 79: A670.

28 Chen G, Suzuki H. Some electrical properties of the endothelium-dependent hyperpolarization recorded from rat arterial smooth muscle cells. J Physiol (Lond) 1989; 410: 91-106.

29 Altiere RJ, Kiritsy-Roy JA, Catravas JD. Acetylcholineinduced contractions in isolated rabbit pulmonary arteries: role of thromboxane $A_{2}$. J Pharmacol Exp Ther 1986; 236: 535-41.

30 Barnes $S D$, Martin LD, Wetzel RC. Halothane enhances pulmonary artery endothelial eicosanoid release. Anesth Analg 1992; 75: 1007-13.

31 Loeb $A L$, O'Brien $D K$, Longnecker DE. Halothane inhibits bradykinin-stimulated prostacyclin production in endothelial cells. Anesthesiology 1994; 81: 931-8.

32 Gambone LM, Flavaban NA, Murray PA. Attenuation of bradykinin-induced vasorelaxation by isoflurane is unmasked by cyclooxygenase inhibition in isolated canine pulmonary arteries. Anesthesiology 1994; 81: A700. 